\title{
ESTIMATION OF COUNTY ECOLOGICAL CIVILIZATION CONSTRUCTION LEVEL IN SICHUAN PROVINCE BASED ON IMPROVED ECOLOGICAL FOOTPRINT MODEL
}

\author{
WANG, X. Y. ${ }^{1}-\mathrm{XIE}, \mathrm{Z} . \mathrm{Y}^{1^{*}}-\mathrm{MA}, \mathrm{Y}^{2}$ \\ ${ }^{1}$ Faculty of School of Economics and Management, North China University of Technology \\ No. 5 Jinyuanzhuang Road, Shijingshan District, Beijing, China \\ ${ }^{2}$ Department of Management and Engineering, Beihang University \\ No. 37 Xueyuan Road, Haidian District, 100191 Beijing, China \\ *Corresponding author \\ e-mail: 867917280@qq.com; phone: +86-185-0019-1013
}

(Received 22 $2^{\text {nd }}$ May 2019; accepted $28^{\text {th }}$ Aug 2019)

\begin{abstract}
The construction of ecological civilization is an important part of the cause of socialism with Chinese characteristics. It concerns the well-being of the people, the future of the nation, the goal of "two hundred years" and the realization of the Chinese dream of great rejuvenation of the nation. County is the basic unit of ecological civilization construction in China. The construction of county ecological civilization is of great significance to that on the national scale. Therefore, how to accurately calculate the level of county ecological civilization construction has become a significant subject. Based on the general situation of Sichuan Province, this paper uses a large number of county data collected from Sichuan Province to calculate the county ecological footprint of Sichuan Province through the improved ecological footprint model. The ecological footprint model is revised based on NPP by GIS technology, which makes the calculation result more accurate and scientifically evaluates the level of County Ecological Civilization Construction in Sichuan Province.
\end{abstract}

Keywords: net primary productivity, ecological deficit, NPP, equilibrium factor, yield factor

\section{Introduction}

First of all, due to the characteristics of simple population composition and small area, county governments have a better understanding of the situation within the scope of management, which is more useful in the process of ecological civilization construction. Secondly, for the counties which are at the key position of implementing national policies, the task of ecological civilization construction is more specific, the space of play is broader, and it is easier to find problems in policy formulation and implementation and solve them timely and accurately. Thirdly, the county level is closer to the grassroots level and the masses, and promoting the construction of county ecological civilization will help making policies more precise to benefit the vast majority of the people. It can be seen that the county ecological civilization construction is the basic unit of the national ecological civilization construction, and is the key and foundation of the ecological civilization construction. Therefore, how to accurately calculate the level of county ecological civilization construction has become a significant subject. Based on the general situation of Sichuan Province, this study uses county data collected in here to measure the county ecological footprint of Sichuan Province through the improved ecological footprint model to measure the level of County Ecological Civilization Construction in Sichuan Province. In the process of 
using the ecological footprint model, the ecological footprint model is modified based on NPP by GIS technology, which makes the calculation result more accurate.

\section{Literature review}

Many studies have been made on the construction of ecological civilization at home and abroad, which mainly concentrates on the concept and connotation, evaluation methods and technical means of ecological civilization construction.

In terms of the concept and connotation of ecological civilization construction: The concepts in this regard have not been unified. Morrison (1995) put forward the concept of "ecological civilization" in 1995. Foreign researches on this concept are mainly based on the ecological study of civilization. Arnason (1998) studied the relationship between Japanese civilization and Marine ecology, and expounded the characteristics of Japanese civilization from the ecological perspective. Quinilley (2011) analyzed the spatial dimensions needed to ensure the development of ecological civilization based on the spatial attributes of ecological environment. Scholar Alakbarov (2015) started with the ecological civilization of Azerbaijani, and studied the impact of human resource development, increasing fixed assets, innovation strategy on ecological knowledge, as well as the relationship between these related issues. In 1987, the ecologist Ye (1987) first applied the concept of ecological civilization. He believed that ecological civilization means that human beings can benefit from nature and return to nature. After the 18th National Congress, both academia and government departments at all levels have expounded their understanding of ecological civilization from many perspectives. Qin et al. (2015) have subdivided the concept of ecological civilization into two dimensions, one is the history of human development, the other is the real social system, corresponding to the broad sense and narrow sense of ecological civilization.

As for the evaluation methods of ecological civilization construction, the main methods include ecological footprint method, real development index method and index system method. Mikuliqi et al. (2016) applied the ecological footprint method in the analysis of cement industry. The research results show that the industry has invested a lot of raw materials in time, but the level of energy utilization has not changed significantly. Bartocci et al. (2016) studied the environmental problems of Sagrantino and Grechetto by using carbon footprint, ecological footprint and water footprint methods respectively. Ferreira et al. (2016) introduced the life cycle assessment theory into the ecological footprint assessment system. Sziget et al. (2016) takes Hungary as the research object to analyze the changes of ecological footprint density in that country in recent years. The ISEW index proposed by scholar H. Daly, that is, the economic welfare index of sustainable development, can be used to replace GDP. Verhofstadt et al. (2016) studies the integration of personal welfare and ecological footprint. Qian et al. (1990) and others used the method of quantitative and qualitative integration to study the giant system. Because in the face of such a huge system, only by building a comprehensive index system, can it be more accurate quantitative research. After this method was put forward, Kong et al. (2016), Ma et al. (2017), Xing (2016) and other Tongdu all applied the index system method to give the corresponding evaluation to the construction of ecological civilization.

As far as the technical means of evaluating the construction of ecological civilization are concerned, in foreign countries, the work of evaluating the construction of ecological civilization can be traced back to the 1960s at the earliest, but only in the 
1970s did it enter the stage of development. Based on this, Remote Sensing (RS), Geographic Information System (GIS) and landscape ecology were developed, and the corresponding ecological evaluation was carried out through them. Lee and Wong (2001) believe that landscape quality and ecological value are closely related. Through GIS and land use data, he evaluated the landscape and ecological value of the analysis area. Based on these results, corresponding management policies are formulated. Smith et al. (1999) used remote sensing, mapping and statistical techniques to analyze the level of land use in the region. Based on remote sensing monitoring data, Espejel (1987), analyzed the ecological status and sustainability of the monitoring area, and constructed different land use conditions in the analysis process. Scholar Reid et al. (2000), based on GIS technology, evaluates the effects of land use and land cover on ecosystem. Tang (2014) took Pengshan County as the research object, and analyzed its defects in the construction of ecological civilization. Lu et al. (2015) based on the space-time comprehensive measurement model and sustainable development evaluation index system, and then according to the technology of gravity center displacement, AHP and GIS, take many districts and counties in Liaoning Province as the research object, and adopt the comprehensive measurement model to study their sustainable development. Liu et al. (2017) are evaluating the sustainable development of Jiangxi Province. Wang and Ren (2018) took Yulin area as the research object, and made a comprehensive evaluation and analysis of the ecological security of the area through remote sensing and GIS technology, and compiled an evaluation index system for the area.

There are many methods to measure the level of regional ecological civilization construction, but the evaluation of the level of regional ecological civilization construction from the county perspective is relatively less. There are many studies on the evaluation of ecological footprint method, but most of them can not improve their inherent defects. The improvement of Ecological Footprint Based on NPP method is relatively rare. This paper studies the integration of improved ecological footprint model and GIS technology, and effectively improves the accuracy of evaluation.

\section{Method selection and data source}

\section{Method selection}

In 1992, W. Rees from Canada first proposed the ecological footprint model, which was improved by $\mathrm{M}$. Wackemagel. The model is an important research tool. It introduces the concept of ecological space size and maps the natural capital consumption and the ecological services supported by natural systems to evaluate the sustainability of human activities. The core of the theory is "bio-production area". With the help of ecological footprint analysis tools, the overall calculation results can be simplified, and the natural capital supply and demand information of the calculated area can be more vividly mapped. However, the ecological footprint model also has some shortcomings, mainly in the following aspects: firstly, the lack of dynamic. Only realtime ecological information can be analyzed, which belongs to a typical static analysis. When calculating the related ecological land area, a definite time is needed. Secondly, the assumption of spatial mutuality is flawed. In this footprint theory, the hypothesis of land spatial exclusion is put forward. However, this hypothesis obviously has defects, that is, land itself has various and replaceable attributes, which divides the whole system. Thirdly, the comparability and reality of equilibrium factors and yield factors 
are difficult to coordinate. Based on the concept of global hectare ecological footprint, it is difficult to get close to the actual situation of the study area, and when calculating the ecological carrying capacity of cultivated land, construction land is usually equated with cultivated land, which invisibly increases the cultivated land area, and the corresponding calculation results will naturally become larger. Because the ecological footprint model has some defects and shortcomings, this study introduced the concept of time series to analyze the economic, natural and social changes of different time nodes. In addition, the parameters used in the traditional footprint model are based on the global perspective, which is lack of accuracy for the study of Sichuan. Therefore, the concept of Net Primary Productivity (NPP) is introduced to make the footprint model play a greater role.

\section{Data sources}

This study focuses on the county-level administrative regions of Sichuan Province. However, due to the sparse land, weak industrial, forestry, fishery and agricultural foundations, the calculation results of ecological footprint in Western Sichuan alpine Tibetan area and Liangshan Yi area are significantly lower than those in other areas, considering the availability of statistical data in some years. This study does not include 48 districts and counties under the jurisdiction of Ganzi Tibetan Autonomous Prefecture, Aba Qiang Autonomous Prefecture and Liangshan Yi Autonomous Prefecture. Therefore, this study selected 135 districts and counties in Sichuan Province (excluding alpine Tibetan areas in Western Sichuan and Liangshan Yi areas in large and small). The data are from Sichuan Yearbook, Sichuan Statistical Yearbook, Sichuan Statistical Bulletin of National Economic and Social Development and statistical yearbooks of cities at all levels in Sichuan Province from 2007 to 2016.

In this study, the ecological footprint of Sichuan counties mainly includes the consumption of bio-resources and fossil energy. According to the consumption of bioresources in Sichuan Province, it mainly includes grain, oil, raw hemp, sugar, tobacco leaves, beef, mutton, rabbit meat, aquatic products, tea, garden fruits, etc. Energy consumption mainly includes Coal, gasoline, kerosene, diesel and natural gas, as shown in Table 1.

Table 1. The indicator of county ecological footprint accounts

\begin{tabular}{c|c|c}
\hline Ecosystem consumption types & Land type & Account index \\
\hline \multirow{3}{*}{ Biological resources account } & Cultivated land & Food, oil crops, raw hemp, sugar, tobacco leaves, vegetables, medicinal materials \\
& Woodland & Garden fruits and tea \\
& Grassland & Pork, beef, mutton, rabbit, milk, eggs, honey, cocoon \\
& Waters & Aquatic product \\
\hline \multirow{2}{*}{ Fossil energy account } & Fossil fuel & Coal, gasoline, kerosene, diesel and natural gas \\
& Building land & Electric power \\
\hline
\end{tabular}

In addition, this study uses MOD17A3 data provided by the National Aeronautics and Space Administration (NASA). The fitting model is BIOME-BGC with a spatial resolution of $1 \mathrm{~km}$. Modis Reprojection Tool (MRT) software provided by NASA is used to process the image mosaic and re-projection. Then ALBERS isoproduct projection is selected to remove outliers and other operations to process the MODIS data, and then NPP value is obtained. ArcGIS 10.2 software is used to clip global 
MODIS data with the help of Sichuan geographic information vector map. The result is shown in Figure 1. In Figure 1, the data of 2006, 2009, 2012 and 2015 are shown respectively. Through the analysis of the above chart can find that the NPP value from east to West shows a decreasing trend, mostly 500-750 gC M 2 a 1. In a word, the low altitude is higher than the high altitude. The land in this province is classified according to the types of resources on the way, and overlapped with the map after cutting. Then the corresponding NPP mean values and corresponding areas of six types of land in Sichuan Province are calculated.
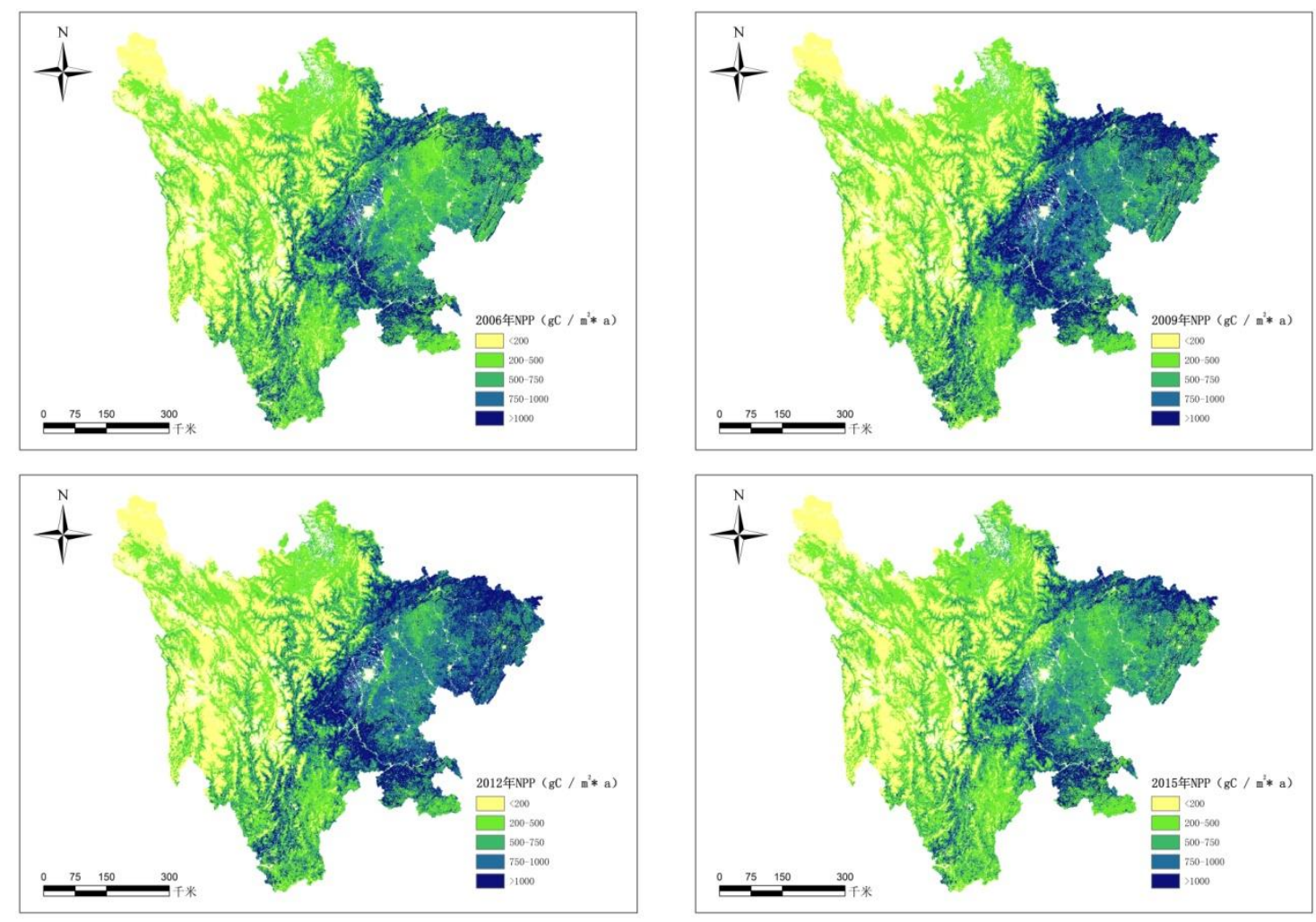

Figure 1. Vegetation NPP spatial distribution of Sichuan Province on 2006, 2009, 2012 and 2015

\section{Adjustment of yield factor and equilibrium factor}

This study applied the concept of "provincial hectare" to study the county ecological footprint of Sichuan Province. The basis of this province's hectare model is still the ecological footprint model. When calculating the output and equilibrium factors of Sichuan Province, the average productivity of the province is used. Equilibrium factors of related types of land are the ratio of their average productivity to other types of average productivity. The so-called yield factor is the ratio of the average productivity of the related types of land in a region to that of the same kind of land in a province. Bio productivity can be expressed by NPP. After removing self-consuming oxygen, green plants produce organic matter per unit time and area, which is called NPP. Therefore, it can be used to express the productivity of plants, and also to show the productivity of different land types, and then more accurately obtain the development level of the study area. NPP in this region needs to calculate NPP value of water area, woodland, 
grassland and cultivated land, and the corresponding area, then weighted sum, the corresponding formula is as follows:

$$
\overline{N P P}=\frac{\sum_{j}\left(A_{j} \times N P P_{j}\right)}{\sum_{j} A_{j}}
$$

In Equation 1: the area of various land types (m2).

The formulas for calculating the four types of land equilibrium factors of cultivated land, woodland, grassland and water area in China are as follows:

$$
r_{j}=\frac{N P P_{j}}{\overline{N P P}}
$$

In Equation 2: It is the average NPP of the land type $j(\mathrm{gC} / \mathrm{m} 2 . \mathrm{a})$ and the average NPP of the land type $(\mathrm{gC} / \mathrm{m} 2 . \mathrm{a})$.

The formulas for calculating the yield factors of cultivated land, woodland, grassland and water area in Sichuan Province are as follows:

$$
y_{i}=\frac{N P P_{j}^{\prime}}{\overline{N P P_{j}}}
$$

In Equation 3: $N P P^{\prime}$ is the average NPP $(\mathrm{gC} / \mathrm{m} 2 . \mathrm{a})$ of all kinds of land types in Sichuan Province and the average NPP ( $\mathrm{gC} / \mathrm{m} 2$.a) of all kinds of land types in China.

\section{Model calculation}

\section{Measuring ecological footprint}

There are six main types of bio-productive area: fossil energy land, construction land, grassland, cultivated forest land, cultivated land and water area. Different types of bio-productive land have different ecological productivity, so it is necessary to introduce the equilibrium factor to calculate the bio-productive area with the world average productivity, so that different types of bio-productive land can be transformed into equivalent ecological productivity and the total ecological footprint can be calculated. Similarly, when calculating the ecological carrying capacity, it is necessary to introduce yield factors to convert the land area of the same ecological productivity in different countries or regions into comparable area. The calculation formula is as follows:

$$
E F=N \times e f=N \times \sum\left(r_{j} \times A_{j}\right)=N \times \sum\left(r_{j} \times\left(c_{j} / p_{j}\right)\right)
$$

In Equation 4, EF represents the total ecological footprint of a region. $N$ is the total population. ef represents the per capita ecological footprint. $r_{j}$ is the equilibrium factor. $A_{j}$ is the ecological productive land area per capita converted from type $j . c_{j}$ is 
the type $i$ per capita consumption. $p_{j}$ is the average production capacity of species $j \cdot j$ is productive land.

\section{Estimation of ecological carrying capacity}

Eco-carrying capacity, also known as biological carrying capacity, refers to the maximum amount of resources and wastes that can be supplied and digested without harming the ecosystem and on the basis of complete productivity and function.

$$
E C=N \times e c=N \times \sum a_{j} \times r_{j} \times y_{j}
$$

In Equation 5, EC is the total ecological carrying capacity of the region. $N$ is the total population. $e c$ is the per capita ecological carrying capacity. $a_{j}$ is per capita Ecoproductive land area. $r_{j}$ is the equilibrium factor. $y_{j}$ is the yield factor.

\section{Estimating the ecological deficit}

The ecological surplus/deficit is determined by comparing the size of EF and EC. When $E F-E C>0$, there will be an ecological deficit; on the contrary, when $E F-E C<0$, there will be an ecological surplus. By comparing the size of EF and EC, the sustainability of social development can be judged. Shengzhi deficit indicates that the human load in the region exceeds its ecological capacity. To meet the consumption demand under the existing living standard, the region either consumes its own natural capital to make up for the shortage of energy supply, or imports the lack of resources from outside the region to make up for the shortage of supply. Its development mode is in an unsustainable state. On the contrary, the ecological surplus indicates that the production and consumption patterns in the region are sustainable, and the human load in the region is within its ecological capacity, and its development pattern is in a sustainable state. The calculation formula is as follows:

$$
e d=e c-e f
$$

In Equation 6: ed is the per capita ecological deficit, when $e d<0$, it is the ecological deficit, when $e d>0$, it is the ecological surplus, ef is the per capita ecological footprint, $e c$ is the per capita ecological carrying capacity.

\section{Empirical results}

\section{Calculations of equilibrium factor and yield factor}

By calculating Equations 1-3, the equilibrium factors and yield factors of various land types in Sichuan Province from 2006 to 2015 are obtained, as shown in Tables 2 and 3. Tables 2 and 3 show only the land equilibrium factors and yield factors in 2006, 2009, 2012 and 2015 as follows.

The values of yield factor and equilibrium factor in the improved ecological footprint model are taken from the values in Tables 2 and 3. 
Table 2. Balance factors for land types in major years in Sichuan Province

\begin{tabular}{c|c|c|c|c}
\hline Land type & $\mathbf{2 0 0 6}$ & $\mathbf{2 0 0 9}$ & $\mathbf{2 0 1 2}$ & $\mathbf{2 0 1 5}$ \\
\hline Grassland & 0.563 & 0.582 & 0.599 & 0.619 \\
Cultivated land & 1.518 & 1.515 & 1.487 & 1.461 \\
Fossil energy & 0.898 & 0.898 & 0.898 & 0.898 \\
Building land & 1.518 & 1.515 & 1.498 & 1.461 \\
Woodland & 1.083 & 1.062 & 1.065 & 1.069 \\
Waters & 1.167 & 1.187 & 1.155 & 1.103 \\
\hline
\end{tabular}

Table 3. Output factors of land types in major years in Sichuan Province

\begin{tabular}{c|c|c|c|c}
\hline Land type & $\mathbf{2 0 0 6}$ & $\mathbf{2 0 0 9}$ & $\mathbf{2 0 1 2}$ & $\mathbf{2 0 1 5}$ \\
\hline Grassland & 1.824 & 1.813 & 1.762 & 1.742 \\
Cultivated land & 1.688 & 1.598 & 1.498 & 1.357 \\
Building land & 1.688 & 1.586 & 1.505 & 1.357 \\
Woodland & 0.727 & 0.752 & 0.729 & 0.681 \\
Waters & 1.557 & 1.520 & 1.408 & 1.270 \\
\hline
\end{tabular}

\section{Calculation results of ecological footprint}

The average ecological footprint, ecological carrying capacity and ecological deficit per capita of 135 county-level administrative units in Sichuan Province were calculated by improved ecological footprint model. Calculate the ecological footprint according to Equation 4. Limited to the length of the article, only selected in 2006, 2000, 2009, 2012 and 2015 to show the ecological footprint per capita, ecological carrying capacity per capita and total ecological deficit per capita of 135 counties and districts in Sichuan Province in the main years. The counties and districts with the first-fifth and 131-135 indicators are shown in Tables 4 and 5, respectively.

Table 4. Counties Ranking 1-5 on per capita ecological footprint of major years in Sichuan

\begin{tabular}{c|c|c|c|c|c|c|c|c|c|c|c}
\hline Ranking & \multicolumn{2}{|c|}{$\mathbf{1}$} & \multicolumn{2}{c|}{$\mathbf{2}$} & \multicolumn{2}{c|}{$\mathbf{3}$} & \multicolumn{2}{c}{$\mathbf{4}$} & \multicolumn{2}{c}{$\mathbf{5}$} \\
\hline Year & County & Value & County & Value & County & Value & County & Value & County & Value \\
2006 & Renshou & 28.14 & Anyue & 27.87 & Santai & 22.09 & Yuechi & 19.64 & Zhong jiang & 18.92 \\
2009 & Anyue & 30.86 & Renshou & 30.03 & Santai & 25.11 & Zhong jiang & 23.33 & Rong & 20.28 \\
2012 & Renshou & 34.69 & Anyue & 33.30 & Yuechi & 30.99 & Zhong jiang & 28.47 & Santai & 27.74 \\
2015 & Renshou & 36.14 & Anyue & 35.87 & Yuechi & 35.31 & Santai & 34.85 & Lu & 33.17 \\
\hline
\end{tabular}

Table 5. Counties ranking 131-135 on per capita ecological footprint of major years in Sichuan

\begin{tabular}{c|c|c|c|c|c|c|c|c|c|c}
\hline Ranking & \multicolumn{2}{|c|}{131} & \multicolumn{2}{c|}{132} & \multicolumn{2}{c|}{$\mathbf{1 3 3}$} & \multicolumn{2}{c}{$\mathbf{1 3 4}$} & \multicolumn{1}{c}{$\mathbf{1 3 5}$} \\
\hline Year & County & Value & County & Value & County & Value & County & Value & County & Value \\
2006 & Cangxi & 2.98 & Yilong & 2.58 & Luojiang & 2.45 & Qionglai & 2.05 & Wusheng & 1.73 \\
2009 & Yu cheng & 3.04 & Cangxi & 2.85 & Yilong & 2.43 & Wan yuan & 2.33 & Wusheng & 1.87 \\
2012 & Ming shan & 3.42 & Wan yuan & 2.63 & Qionglai & 2.38 & Yilong & 2.05 & Wusheng & 1.68 \\
2015 & Yu cheng & 3.94 & Cuiping & 3.82 & Wanyuan & 2.87 & Yilong & 2.08 & Wusheng & 1.76 \\
\hline
\end{tabular}


Tables 4 and 5 show the per capita ecological footprint of counties in Sichuan Province in the main years. From the table, it can be seen intuitively that the top five and the last five counties in the per capita ecological footprint have great differences in numerical value. Especially in 2012, the per capita ecological footprint of Renshou County ranked first reached 30.86, 20.65 times that of Wusheng County ranked 135. Secondly, from the perspective of trend, from 2006 to 2015, the per capita ecological footprint of counties in Sichuan Province shows an increasing trend year by year. Especially in the period of 2012-2015, the growth rate accelerated significantly. Thirdly, by analyzing the counties with large per capita ecological footprint can find that most of the counties with high ranking, such as Renshou County, Anyue County, Santai County, Luxian County and Zhongjiang County, are the main producing areas of agricultural products in the province and have a large population base.

\section{Calculation results of ecological carrying capacity}

According to Equation 5, the ecological carrying capacity is calculated. The results are shown in Tables 6 and 7.

Table 6. Counties ranking 1-5 on per capita ecological capacity of major years in Sichuan

\begin{tabular}{c|c|c|c|c|c|c|c|c|c|c}
\hline Ranking & \multicolumn{2}{|c|}{$\mathbf{1}$} & \multicolumn{2}{c|}{$\mathbf{2}$} & \multicolumn{2}{c|}{$\mathbf{3}$} & \multicolumn{2}{c}{$\mathbf{4}$} \\
\hline Year & County & Value & County & Value & County & Value & County & Value & County & Value \\
2006 & Mabian & 1.23 & Pingwu & 1.21 & Qing chuan & 1.15 & Wang cang & 1.02 & Ebian & 1.01 \\
2009 & Pingwu & 1.21 & Mabian & 1.20 & Qing chuan & 1.13 & Wan yuan & 1.03 & Wangcang & 1.00 \\
2012 & Mabian & 1.21 & Pingwu & 1.19 & Qing chuan & 1.08 & Wang cang & 1.04 & Wanyuan & 0.96 \\
2015 & Mabian & 1.19 & Qingchuan & 1.00 & Wang cang & 0.99 & Pingwu & 1.15 & Baoxing & 0.93 \\
\hline
\end{tabular}

Table 7. Counties ranking 131-135 on per capita ecological capacity of major years in Sichuan

\begin{tabular}{c|c|c|c|c|c|c|c|c|c|c}
\hline Ranking & \multicolumn{2}{|c|}{131} & \multicolumn{2}{c|}{132} & \multicolumn{2}{c|}{$\mathbf{1 3 3}$} & \multicolumn{2}{c}{$\mathbf{1 3 5}$} \\
\hline Year & County & Value & County & Value & County & Value & County & Value & County & Value \\
2006 & Shuang liu & 0.15 & Dazhu & 0.12 & Xuanhan & 0.11 & Weiyuan & 0.10 & Qu & 0.08 \\
2009 & Shuang liu & 0.13 & Xuanhan & 0.12 & Dazhu & 0.11 & Weiyuan & 0.10 & Qu & 0.09 \\
2012 & Shuang liu & 0.12 & Dazhu & 0.11 & Xuanhan & 0.10 & Qu & 0.08 & Weiyuan & 0.07 \\
2015 & Shuang liu & 0.12 & Dazhu & 0.10 & Xuanhan & 0.09 & Qu & 0.06 & Weiyuan & 0.05 \\
\hline
\end{tabular}

Tables 6 and 7 show the main years in Sichuan province county per capita ecological carrying case, can be seen from the table, the per capita ecological carrying capacity in 2006-2015, there is no significant change, but in the top five and five districts after from the numerical difference is bigger, especially in 2012, the number one cause of Mabian County per capita ecological carrying capacity is 1.21, 23.8 times is ranked 135th in Weiyuan. Secondly, in terms of trend, unlike the per capita ecological footprint, the per capita ecological carrying capacity of counties in Sichuan Province does not generally show a decreasing trend year by year, and the per capita ecological carrying capacity of some districts and counties has increased. Thirdly, by analyzing the counties with larger per capita ecological carrying capacity in Sichuan Province will find that Mabian County, Pingwu County, Qingchuan County, Wancang County, Wanyuan County, Baoxing County and Ebian County are the key ecological functional counties in 
Sichuan Province, with the distribution of national-level nature reserves such as Dafeng Ding, Xuebaoding, Wang Lang, Tangjiahe, Micang Mountain, Huacalyx Mountain, Beepupa Village, Heizhugou Valley, Jiajinshan and so on. Domestic forest park, under the improved ecological footprint algorithm based on NPP, has a certain role in improving the ecological carrying capacity of the region.

\section{Calculation results of ecological deficit}

According to Equation 6, the ecological deficit is calculated. The results are shown in Tables 8 and 9.

Table 8. Counties ranking 1-5 on per capita ecological deficit of major years in Sichuan

\begin{tabular}{c|c|c|c|c|c|c|c|c|c|c}
\hline Ranking & \multicolumn{2}{|c|}{$\mathbf{1}$} & \multicolumn{2}{c|}{$\mathbf{2}$} & \multicolumn{2}{|c|}{$\mathbf{3}$} & \multicolumn{2}{c}{$\mathbf{4}$} \\
\hline Year & County & Value & County & Value & County & Value & County & Value & County & Value \\
2006 & Renshou & 27.56 & Anyue & 27.20 & Santai & 21.50 & Yuechi & 19.18 & Zhong jiang & 18.38 \\
2009 & Anyue & 30.21 & Renshou & 29.46 & Santai & 24.55 & Zhong jiang & 22.72 & Rong & 19.67 \\
2012 & Renshou & 34.01 & Anyue & 32.70 & Yuechi & 30.33 & Zhong jiang & 27.89 & Santai & 27.12 \\
2015 & Renshou & 35.56 & Anyue & 35.27 & Yuechi & 34.73 & Santai & 34.24 & Lu & 32.58 \\
\hline
\end{tabular}

Table 9. Counties ranking 131-135 on per capita ecological deficit of major years in Sichuan

\begin{tabular}{c|c|c|c|c|c|c|c|c|c|c}
\hline Ranking & \multicolumn{2}{|c|}{131} & \multicolumn{2}{c|}{132} & \multicolumn{2}{c|}{133} & \multicolumn{2}{c}{$\mathbf{1 3 4}$} & \multicolumn{1}{c}{$\mathbf{1 3 5}$} \\
\hline Year & County & Value & County & Value & County & Value & County & Value & County & Value \\
2006 & Cangxi & 2.27 & Yilong & 1.88 & Luo jiang & 1.77 & Qionglai & 1.35 & Wusheng & 1.01 \\
2009 & Yucheng & 2.33 & Cangxi & 2.16 & Yilong & 1.70 & Wan yuan & 1.60 & Wusheng & 1.10 \\
2012 & Ming shan & 2.71 & Wan yuan & 1.90 & Qionglai & 1.66 & Yilong & 1.31 & Wusheng & 0.98 \\
2015 & Yucheng & 3.23 & Cuiping & 3.18 & Wan yuan & 2.17 & Yilong & 1.33 & Wusheng & 1.06 \\
\hline
\end{tabular}

Tables 8 and 9 show the per capita ecological deficit of counties in Sichuan Province in the main years. As mentioned above, the per capita ecological deficit is the difference between the per capita ecological footprint and the per capita ecological carrying capacity. However, from the calculation results, the difference between the per capita ecological carrying capacity and the per capita ecological footprint in Sichuan Province is very large. The ranking of the per capita ecological deficit is basically the same as that of the per capita ecological footprint. The ecological footprint of each county in Sichuan Province is far greater than that of the ecological carrying capacity.

The result of comprehensive evaluation shows that the per capita standard can reduce the error caused by population differences and make the calculation more reliable. It is feasible to evaluate the ecological footprint, ecological carrying capacity and ecological deficit based on the improved ecological footprint model. The evaluation shows that the ecological environment carrying capacity of the districts and counties in Sichuan Province is generally good, but there are great differences among the districts and counties, which are different from Shi et al. (2013). Agriculture, industrialization and fishery, represented by arable land, construction land and water area, are the core elements to evaluate the ecological carrying capacity. Industrialization is the root cause of the increase in energy and consumption, which is partly consistent with the conclusions of Zhao et al. (2008). The development of construction industry promotes 
the transfer of rural surplus labor force, but also provides convenient conditions for industrial transformation and upgrading.

\section{Conclusion}

Because of the traditional ecological footprint model has certain defects, this article through the use of software and the MRT ArcGIS10.2 software of 1:100000 in Sichuan in 2006-2015 data of land use (geographic conditions monitoring cloud platform) and MOD17A3 data for Mosaic and projection, eliminate outliers, multiplied by the scale factor, the MODIS data into NPP actual value, represented the biological productivity of land with a NPP, improve the ecological footprint model of production factor and the equilibrium factor in order to closer to the actual of Sichuan province. Through the improvement of the ecological footprint model 135 counties of Sichuan province county per capita ecological footprint in 2006-2015, the per capita ecological carrying capacity and ecological deficit per capita, the results can be seen that all present in the study area of ecological deficit and increased year by year, the overall ecological environment extremely safe state for a long time, the development of sustainability. But at the same time, after 2012 because many counties began to emphasize the importance of ecological civilization construction in the development of county economy, the trend of high-speed growth of ecological footprint in some counties has not only been curbed, but also a trend of decreasing ecological footprint. For regions with too large ecological footprint, it is necessary to establish and improve the evaluation mechanism reflecting the requirements of ecological civilization, incorporate the construction of ecological civilization into the evaluation index system of county-level government's economic and social development performance objectives, increase the weight of assessment, and strengthen the constraints of indicators. a differentiated performance appraisal system will be implemented, explore the preparation of balance sheets for natural resources, and conduct outgoing audits of natural resources assets and environmental responsibilities for leading cadres. This also requires that Sichuan counties and districts in the formulation of county economic development strategy can not blindly compare, like great success, but need to take full account of their ecological conditions, in accordance with their own county conditions, so as to adapt to local conditions.

In future research, we should make full use of remote sensing technology, strengthen early warning of regional ecological carrying capacity, and provide scientific guarantee services for national county development policies to ensure sustainable development of regional ecology.

Acknowledgements. The authors acknowledge Research Start-up Funds of North China University of Technology (110051360002); Basic Scientific Research Project of the Beijing Municipal Education Commission in 2018 (110052971921).

\section{REFERENCES}

[1] Alakbarov, U., Lawrence, J. E. (2015): Towards ecological civilization: ideas from Azerbaijan. - Journal of Human Resource and Sustainability Studies 3(3): 93.

[2] Arnason, R. (1998): Ecological fisheries management using individual transferable share quotas. - Ecological Applications 8(sp1): S151-S159. 
[3] Bartocci, P., Fantozzi, P., Fantozzi, F. (2017): Environmental impact of Sagrantino and Grechetto grapes cultivation for wine and vinegar production in central Italy. - Journal of Cleaner Production 140: 569-580.

[4] Espejel, I. (1987): A phytogeographical analysis of coastal vegetation in the Yucatan Peninsula. - Journal of Biogeography 14(6): 499-519.

[5] Ferreira, V. L., Torregrosa-López, J. I., Capuz-Rizo, S. F. (2016): Use of life cycle assessment methodology in the analysis of ecological footprint assessment results to evaluate the environmental performance of universities. - Journal of Cleaner Production. DOI: $10.1016 /$ j.jclepro.2016.05.046.

[6] Kong, L., Liu, W., Zhang, L. (2016): Study on the construction of evaluation index system of county ecological civilization construction - take Puer City as an example. Forestry Economy 3: 30-33.

[7] Lee, J., Wong, D. W. (2001): Statistical Analysis with ArcView GIS. - John Wiley \& Sons, New York.

[8] Liu, H., Yin, J., Chen, J., Chen, X. (2017): Sustainable development evaluation of Jiangxi Province based on ecological footprint. - Surveying and Mapping Science 5: 62-69.

[9] Lu, C., Zhang, L., Xue, B. (2015): Spatio-temporal comprehensive measurement of regional sustainable development in Liaoning Province. - Economic Geography 8: 32-39.

[10] Ma, Y., He, B., Ma, Z., Lin, Z., Luan, W. (2017): Study on the index system of county eco-civilization construction in agricultural and pastoral areas: taking Huocheng County of Xinjiang as an example. - Journal of Xinjiang University 1: 102-107.

[11] Mikulčić, H., Cabezas, H., Vujanović, M., Duić, N. (2016): Environmental assessment of different cement manufacturing processes based on emergy and ecological footprint analysis. - Journal of Cleaner Production 130: 213-221.

[12] Morrison, R. (1995): Ecological Democracy. - South End Press, Boston.

[13] Qian, X., Yu, J., Dai, R. (1990): A new field of science - open complex giant system and its methodology. - Journal of Nature 1: 3-10.

[14] Qin, H., Yuan, Z., Qin, J. (2015): Research progress in promoting ecological civilization in China. - Population Resources and Environment in China 2: 111-120.

[15] Quilley, S. (2011): Entropy, the anthroposphere and the ecology of civilization: an essay on the problem of 'liberalism in one village' in the long view. - The Sociological Review 59: 65-90.

[16] Reid, R. S., Kruska, R. L., Deichmann, U., Thornton, P. K., Leak, S. G. (2000): Human population growth and the extinction of the tsetse fly. - Agriculture, Ecosystems \& Environment 77(3): 227-236.

[17] Shi, Y., Yin, C., Wang, H., et al. (2013): Research progress and prospect on urban comprehensive carrying capacity. - Geographical Research 32(1): 133-145.

[18] Smith, W., Meredith, T. C., Johns, T. (1999): Exploring methods for rapid assessment of woody vegetation in the Batemi Valley, North-central Tanzania. - Biodiversity \& Conservation 8(4): 447-470.

[19] Szigeti, C., Toth, G., Szabo, D. R. (2017): Decoupling-shifts in ecological footprint intensity of nations in the last decade. - Ecological Indicators 72: 111-117.

[20] Tang, L. (2014): Research on Science and Technology Support in County Ecocivilization Construction. - Chengdu University of Technology, Chengdu.

[21] Verhofstadt, E., Van Ootegem, L., Defloor, B., Bleys, B. (2016): Linking individuals' ecological footprint to their subjective well-being. - Ecological Economics 127: 80-89.

[22] Wang, X. F., Ren, Z. (2008): Study on dynamic change of vegetation coverage in Yulin city based on RS and GIS. - Journal of Shaanxi Normal University (Natural Science Edition) 36(3): 1014.

[23] Xing, J. (2016): Study on the Path of Low-Carbon Economic Development in the Pilot Demonstration Area of County Ecological Civilization. - Shanxi University of Finance and Economics, Shanxi. 
[24] Ye, Q. (1987): The era of true civilization has just begun. Professor Ye Qianji calls for "ecological civilization construction". - China Environment Daily 23: 3.

[25] Zhao, W., Li, J., Chen, Y. (2008): Changes of eco-capacity and ecological sustainability in the north Tian shan Mountains region: taking Fukang County as a case of study. - Acta Ecologica Sinica 28(9): 4363-4371. 